\title{
BMJ Open Demographic and behavioural risk factors associated with Trichomonas vaginalis among South African HIV- positive men with genital ulcer disease: a cross-sectional study
}

Iddrisu Abdallah, ${ }^{1}$ Elizabeth Armstrong-Mensah, ${ }^{2}$ Ernest Alema-Mensah, ${ }^{3}$ Cheryl Jones ${ }^{3}$

To cite: Abdallah I, ArmstrongMensah E, Alema-Mensah E, et al. Demographic and behavioural risk factors associated with Trichomonas vaginalis among South African HIV-positive men with genital ulcer disease: a crosssectional study. BMJ Open 2017;7:e013486. doi:10.1136/ bmjopen-2016-013486

- Prepublication history for this paper is available online. To view these files, please visit the journal online (http://dx.doi. org/10.1136/bmjopen-2016013486).

Received 22 July 2016 Revised 27 May 2017 Accepted 9 June 2017

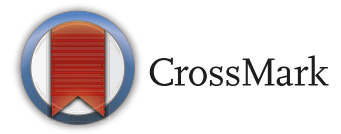

${ }^{1}$ ICF International, Brookhaven, Georgia, USA

${ }^{2}$ School of Public Health, Georgia State University, Atlanta, Georgia, USA

${ }^{3}$ Graduate Education in Public Health, Morehouse School of Medicine, Atlanta, Georgia, USA

Correspondence to Iddrisu Abdallah; abdie@email.com, iddrisu. abdallah@icfi.com

\section{ABSTRACT}

Objectives Demographic and risky sexual behaviours may increase the risk for Trichomonas vaginalis (TV) infection and, thus, enhance HIV transmission to uninfected partners. We assessed the demographic and behavioural risk factors associated with TV among South African HIVpositive men with genital ulcer disease.

Methods We conducted a cross-sectional study with data from a randomised controlled trial conducted by the Centers for Disease Control and Prevention and the London School of Hygiene and Tropical Medicine. The data were obtained from three primary healthcare clinics in South Africa. At baseline ( $n=387)$, participants reported on demographics, sexual behaviour, history of sexually transmitted infections and clinical ulcers. The outcome TV was measured using real-time multiplex PCR assays and a Rotor-gene 3000 platform from the first and past urine samples of all participants. Logistic regression model estimated ORs and 95\% Cls adjusted for demographics, sexual risk behaviours and ulcer conditions.

Results An estimated $11.4 \%$ of TV was detected among the men. The odds of TV infection were significantly associated with high blister counts (OR 4.0, 95\% $\mathrm{Cl} 1.6$ to $28, p=0.01$ ), ulcer pain (OR $0.4,95 \% \mathrm{Cl} 0.2$ to 0.7 , $\mathrm{p}=0.003)$, number of days with ulcers $(0 \mathrm{R} 0.4,95 \% \mathrm{Cl}$ 0.2 to $0.8, p=0.006)$, sought treatment before coming into clinics (OR 0.07, 95\% $\mathrm{Cl} 0.002$ to $0.7, \mathrm{p}=0.005$ ) and being unqualified worker (OR 2.5, 95\% $\mathrm{Cl} 0.9$ to $6.7 \mathrm{p}=0.05$ ). Multivariate analyses revealed that increased days with ulcers (OR $0.1,95 \% \mathrm{Cl} 0.04$ to $0.5, \mathrm{p}=0.002$ ) and ulcer pain intensity (OR $0.08,95 \% \mathrm{Cl} 0.007$ to $1.1, \mathrm{p}=0.05)$ remained significantly associated with decreased odds of TV infection. Men from the Sotho ethnic group were eight times more likely to have TV infection (OR 8.6, 95\% Cl 1.3 to 55.7, $p<0.02$ ) than men from the other ethnic groups. Conclusion HIV-positive men with severe ulceration should be screened and treated for TV to minimise HIV transmission to uninfected partners.

\section{INTRODUCTION}

Trichomoniasis is a sexually transmitted infection (STI) caused by the protozoan parasite,

\section{Strengths and limitations of this study}

- The positive associations revealed by this study showed that men with severe forms of genital ulcer diseases and risky sexual behaviours are more likely to have Trichomonas vaginalis (TV) infection. These associations provide additional evidence pointing to the need for researchers to focus on TV screening and treatments in clinical settings.

- The outcome of this study has practical relevance for HIV interventions since TV may impact the forward transmission of HIV to uninfected partners.

- The relatively small sample size of the study restricts findings to the population studied and, thus, reduces external validity.

- There may have been under-reporting of certain risky sexual behaviours, as the interview relied to a great extent on the men's ability to recall those behaviours.

Trichomonas vaginalis (TV). The infection is transmitted from an infected person to an uninfected person through direct skinto-skin contact and through vaginal intercourse. In women, TV usually infects the lower genital tract (vulva, vagina, cervix or urethra), and in men, it infects the inside of the penis (urethra). While TV occurs in both women and men, it is more prevalent in the former than in the latter, with women being more symptomatic than men. In men, where there are symptoms, there is irritation inside the penis, burning after urination or ejaculation, or discharge from the penis. ${ }^{1}$ Irrespective of being the most common curable STI, TV is the most prevalent non-viral STI globally, with an estimated 174 million new cases annually. $^{2} 3$ Of these cases, approximately 32 million occur in sub-Saharan Africa. $^{2}{ }^{3}$ Compared with other countries in 
sub-Saharan Africa, the incidence of TV in South Africa is high. This is evidenced by the number of patients who visit STI and antenatal clinics in that country. ${ }^{45}$ A review of STI prevalence in South Africa reported an estimated TV prevalence of $20 \%$ in men, with an excess of $20 \%$ prevalence among women in antenatal and STI clinics. TV infection has been linked with an increased risk and transmission of HIV infection. ${ }^{5}$ At present, studies on TV tend to focus more on women than on men. This can be attributed to the impact of the infection on women's health and the fact that the infection produces symptoms in women that can be seen and studied as opposed to men who are usually asymptomatic. As the presence of TV in men is also a risk factor for HIV infection and transmission, it is important that additional studies on the impact of the infection on men be conducted, especially in South Africa, where the infection is also the main cause of most male urethritis and prostatitis. ${ }^{45}$

Even though genital ulcers have been listed as a risk factor for HIV-1, infection with TV can also amplify and increase HIV transmission to discordant sexual partners. ${ }^{67}$ The presence of TV among HIV-positive men with genital ulcer disease (GUD) has been shown to increase ulcer HIV viral load. ${ }^{8}$ In their study, Paz-Bailey et al found that men with TV infection had higher ulcer viral loads on average than those who were not infected with TV. ${ }^{7}$

While there are studies on $\mathrm{TV},{ }^{9}{ }^{10}$ they often tend to focus on the infection with respect to either HIV infection $^{11} 12$ or genital ulcers. ${ }^{13}{ }^{14}$ Consequently, there is a dearth of data on risky behaviours associated with TV infection particularly among men and, even more so, among men who are HIV positive and have GUDs. This paper sought to examine this association. It focused on the relationship between TV, demographics and risky sexual behaviour among male patients with GUD who are HIV positive in South Africa.

\section{METHODS}

\section{Participants and setting}

The design, recruitment methods and participants of the individually randomised, double-blinded, placebo-controlled trial components of the study have been published elsewhere. ${ }^{14}$ This secondary study used baseline data $(n=387)$ from the original trial, which was conducted at three primary healthcare clinics in Johannesburg and Pretoria in South Africa, to measure the effect of acyclovir on GUD among men in South Africa (Clinicaltrials.gov; NCT00164424) from 2005 to $2006 .{ }^{14}$

Men who attended the clinics and were found to have genital ulcers were enrolled in the trial, after their informed consent was obtained. The informed consent form was translated into the main languages spoken in the area: Sotho, Setswana, Zulu and Xhosa. All participants were informed in their own language about the study requirements and the benefits available to them. The translated consent forms were re-assessed for readability and content. After consenting all eligible participants, the forms were then translated back to English and re-assessed. A thumbprint was requested as proof of consent from participants who were unable to sign. All participants were provided with copies of the informed consent form. This study includes all HIV-positive men at baseline. All study participants were tested on site, using two sequential tests for HIV based on the South African HIV testing algorithm. The median CD4 count and plasma HIV-1 load were 282 cells $/ \mathrm{mm}^{3}$ and 87200 copies $/ \mathrm{mL}$, respectively. ${ }^{8}$ A total of 2.7\% (9/333) of the men were on antiretroviral therapy. Study participants were also screened for STIs through serological and molecular methods. At baseline, a questionnaire was administered to collect information on demographics, sexual behaviour and clinical characteristics of the ulcers. The protocol for this secondary study was approved by the Morehouse School of Medicine Institutional Review Board.

\section{Measurements}

Variables relevant to this study were extracted from the baseline data and a subset data was created based on the research question. Sociodemographic variables included age, education, religion, occupation, nationality, marital status, ethnicity, antiretroviral usage and circumcision. The ethnicity question covered the four main ethnic groups in South Africa (Xhosa, Zulu, Sotho and Tsonga). The other category was created to capture the men who were not South African natives and who did not belong to the four listed ethic groups. Regarding occupation, qualified worker referred to individuals who had technical skills or experience in performing a job with or without some level of education. This category offered more occupational options for participants, as majority of the work force in South Africa fall under this category. ${ }^{15}$ The tertiary education variable referred to college or technical level education. Sexual behaviour variables included the number of regular sexual partners (main partner), the number of sexual partners in the past week or 3 months (including casual sex partners), condom use, the number of times they had sex last week and sex with a man and sexual intercourse with ulcer. The measurement of ulcer characteristics focused on ulcer pain intensity, number of days with ulcers and number of ulcer and blister counts at physical examination. The outcome measure of TV was detected using real-time multiplex PCR assays and a Rotor-gene 3000 platform from the first past urine of all the men. This method identified men already infected with TV at baseline, and this determined TV impact on HIV-1 shedding in ulcers. The impact of TV on ulcer HIV viral load has already been published elsewhere. ${ }^{14}$ The outcome measure was dichotomized: TV positive or TV negative. Dependent variables included demographics, reported risky sexual behaviours and measured ulcer conditions.

\section{Statistical analyses}

Descriptive analyses consisted of $\chi^{2}$ bivariate differences in demographic factors, categorical sexual risk 
behaviour and some ulcer characteristics by TV. Associations between TV and related categorical variables were summarised with ORs and a 95\% CI. Continuous variables were presented as means and a two-sample t-test was performed to test the means between groups. Missing data were not included in the analysis. The analyses could not be stratified based on sexual orientation due to the small number of responses for the question $(n=4)$ $(1.03 \%)$. Fisher's exact test was used to compare discrete outcomes in cases of fewer than five responses per cell. Based on frequency distribution, variables with response counts more than $50 \%$ were grouped into one category for analyses purposes. Some variables with responses of more than two categories were re-coded and grouped into two categories for analyses.

Multivariate logistic regression analyses tested associations between TV and other covariates. All variables associated with the outcome variable that had a $p$ value $<0.10$ in the bivariate analysis were initially included in the model and were only retained if they remained statistically significant at $p<0.05$. Some variables showed significance after bivariate analysis, but were not included in the model because they had low cell counts and their inclusion did not yield good results. Since TV-related risks vary by certain sociodemographic factors, ${ }^{910}$ we included age, marital status and level of education on the model. We controlled for variables that could potentially confound associations between the independent (outcome) and dependent variables. Data analysis was performed using SAS 9.3 Enterprise for Windows (V.12.1, 2010, SAS Institute).

\section{RESULTS}

TV was detected in $11.4 \%$ of the urine samples from the men. The mean age of the men was 32.46 years (SD 7.5). Majority of the men were South African natives $(73.83 \%)$ and the remaining were of other nationalities $(25.91 \%)$. The ethnic groups that presented for the study were Zulu (45.99\%), Xhosa (4.39\%), Sotho $(8.79 \%)$, Tsonga $(11.11 \%)$ and other $(29.72 \%)$. Most of the men were unqualified workers and unemployed $(27.65 \%$ and $36.18 \%$, respectively), with qualified and professional workers making up a small fraction of the sample ( $16.80 \%$ and $0.52 \%$, respectively). As shown in table 1 , a large proportion of the men had high school education $(68.99 \%)$, followed by no education (6.98), less than primary school education $(5.17 \%)$, primary school education $(14.73 \%)$ and tertiary education $(3.88 \%)$. In terms of marital status, $52.71 \%$ of the men were single and $24.81 \%$ were married or cohabitating.

Regarding sexual behaviour variables, almost all the men $(97.69 \%)$ reported having at least one regular sexual partner. Over $50 \%$ of the men reported never using condoms with either a regular partner or casual partners and having sex more than six times per week. The number of men with ulcers who never used condoms during sex were higher $(62.77 \%)$ compared with those who used condoms sometimes or always (37.23\%). A few men $(29.95 \%)$ reported having one or more contact with a sex worker in the past 3 months. In general, a good number of the men were sexually active, as they report having sex one to five times in the past week $(47.65 \%)$.

With respect to ulcer condition, majority $(70.59 \%)$ of the men indicated that ulcer pain was bearable and $29.41 \%$ reported unbearable ulcer pain that required an analgesic for relief. Almost all the men (98.45\%) had had the ulcers for more than 5 days before the baseline and had sought care elsewhere before visiting the clinics. While all the men had at least one ulcer $(100 \%)$, the number of blisters counted at the physical exams were low $(8.73 \%)$. More than half of the men had sores on their genitals before the baseline (58.36). A few men (2.70\%) reported using antiretroviral therapy. A great number of the men $(87.50 \%)$ were not circumcised.

Bivariate unadjusted analyses revealed an association between ulcer conditions and TV infection (table 2). Men who reported higher numbers of blisters (OR 4.0, 95\% CI 1.6 to $28.3, \mathrm{p}=0.01$ ) were four times more likely to have TV infection than those who did not. Reports on ulcer pain and pain intensity were inversely associated with TV infection (OR 0.3, 95\% CI 0.2 to $0.8, \mathrm{p}=0.006$ and OR 0.4 , $95 \%$ CI 0.2 to $0.7, \mathrm{p}=0.003$ ) (table 2 ). This association was observed among men who frequently sought for treatment before visiting the clinic (OR 0.07, 95\% CI 0.001 to $1.2, \mathrm{p}<0.001)$. There were increased odds for TV infection among men who had ulcers for more than 11 days (OR 3.3, 95\% CI 1.5 to 7.3, $\mathrm{p}=0.002$ ) than those who had ulcers for less than 6 days. Similar increased odds for TV infection was observed among men who were unqualified workers (OR 2.5, 95\% CI 0.9 to 6.7, $\mathrm{p}=0.05$ ). Also, men from the Sotho ethnic group were three times more likely to have TV infection than those from the other ethnic groups (OR 3.0, 95\% CI 0.9 to 9.0, $\mathrm{p}=0.05$ ). When evaluating risky sexual behaviours as continuous variables, we confirmed a significant association with TV infection. The men were significantly more likely $(\mathrm{p}<0.0001)$ to have TV infection if they had an average of 1.4 regular partners (95\% CI 0.6 to 1.5$)$ and had sex 3.4 times the past week (95\% CI -1.1 to 7.9$)$. The men were significantly less likely $(\mathrm{p}<0.0001)$ to have TV infection if they had an average of 0.39 sexual partners in the past 3 months $(95 \%$ CI 0.1 to 0.6 ). The remaining sexual behaviour and ulcer characteristic variables were not significantly associated with TV infection.

In the multivariate analyses (table 3), TV infection was associated with men who were from the Sotho ethnic group. Among Sotho men, the odds of TV infection were 8.6 times more likely than for men from other ethnic groups (OR 8.6, 95\% CI 1.3 to 55.7, p=0.02). Again, multiple days with ulcer and intense ulcer pain remained significantly associated with decreased odds of TV infection. The odds of TV infection among men who had ulcers for between 6 and 10 days and more than 11 days were less likely compared with those who had ulcers for at most 5 days (OR $0.1,95 \%$ CI 0.04 to $0.5, \mathrm{p}=0.002$ and 
Table 1 Description of study participants, South Africa, 2006

\section{Characteristic}

Value $(\mathrm{n}=387)$

Sociodemographic and behavioural characteristics

Age (years), mean age $(n=387)$ (mean age $\pm S D, 32.46 \pm 7.58$ )

$\begin{array}{ll}18-24 & 49(12.66) \\ 25-34 & 212(54.78) \\ 35+ & 126(32.56)\end{array}$

Ethnic group

\begin{tabular}{|c|c|}
\hline Xhosa & 17 (4.39) \\
\hline Zulu & $178(45.99)$ \\
\hline Sotho & $34(8.79)$ \\
\hline Tsonga & $43(11.11)$ \\
\hline Other & $115(29.72)$ \\
\hline \multicolumn{2}{|l|}{ Nationality } \\
\hline South African & 285 (73.83) \\
\hline Other & $100(25.91)$ \\
\hline \multicolumn{2}{|l|}{ Occupation } \\
\hline Unqualified worker & $107(27.65)$ \\
\hline Qualified worker & $65(16.80)$ \\
\hline Professional & $2(0.52)$ \\
\hline Unemployed & $140(36.18)$ \\
\hline Student & $5(1.29)$ \\
\hline Other & $68(17.57)$ \\
\hline \multicolumn{2}{|l|}{ Marital status } \\
\hline Single & $204(52.71)$ \\
\hline Married/cohabitating & $162(24.81)$ \\
\hline Divorced/separated/widowed & $21(5.43)$ \\
\hline \multicolumn{2}{|l|}{ Level of education } \\
\hline No school & $27(6.98)$ \\
\hline Less than primary (standard 1-2) & $20(5.17)$ \\
\hline Primary (standard 3-5) & $57(14.73)$ \\
\hline High school (standard 6-10) & $267(68.99)$ \\
\hline Tertiary & $15(3.88)$ \\
\hline \multicolumn{2}{|l|}{ Regular partner } \\
\hline No & $48(12.47)$ \\
\hline Yes & $337(87.53)$ \\
\hline \multicolumn{2}{|l|}{ Current regular partner } \\
\hline No & $48(12.47)$ \\
\hline Yes & $337(87.53)$ \\
\hline \multicolumn{2}{|l|}{ Number of regular partners } \\
\hline 0 & $11(2.31)$ \\
\hline 1 & $266(77.55)$ \\
\hline $2+$ & 65 (18.95) \\
\hline
\end{tabular}

Number of sexual partners in the last 3 months (not including regular partners)

\begin{tabular}{rr} 
None $10(3.27)$ \\
\hline Continued
\end{tabular}

Table 1 Continued

\begin{tabular}{cl}
\hline Characteristic & Value $(\mathbf{n}=\mathbf{3 8 7})$ \\
\hline 1 & $234(76.47)$ \\
$2+$ & $62(20.26)$
\end{tabular}

Condom use with regular partners

$\begin{array}{ll}\text { Never } & 187(55.33) \\ \text { Sometimes/most of the time } & 101(29.88) \\ \text { Always } & 50(14.79)\end{array}$

Condom use with casual partners in the last 3 months

\begin{tabular}{|ll} 
Never & $168(55.45)$ \\
\hline $\begin{array}{l}\text { Sometimes/most of the time } \\
\text { Always }\end{array}$ & $92(30.36)$ \\
\hline $\begin{array}{l}\text { Number of times had sex in last week } \\
\text { None }\end{array}$ & $43(14.19)$ \\
\hline $1-5$ & $168(49.51)$ \\
\hline $6+$ & $162(47.65)$ \\
\hline
\end{tabular}

Money in exchange for sex

$\begin{array}{ll}\text { No } & 295(86.26) \\ \text { Yes } & 47(13.74)\end{array}$

Findings at physical exams

Circumcision

$\begin{array}{ll}\text { No } & 175(87.50) \\ \text { Yes } & 25(12.50)\end{array}$

Number of days with ulcer before baseline

$\begin{array}{ll}0-5 & 172(50.89) \\ 6-10 & 96(28.40) \\ 11+ & 70(20.71)\end{array}$

Seek care elsewhere before coming to clinic

$\begin{array}{ll}\text { No } & 5(1.47) \\ \text { Yes } & 336(98.53)\end{array}$

Number of times sought care before coming to clinic

\begin{tabular}{|cr}
0 & $49(38.58)$ \\
1 & $64(50.39)$ \\
$2+$ & $14(11.02)$ \\
Number of times had sores in last 12 months
\end{tabular}

Number of times had sores in last 12 months

\begin{tabular}{|ll}
\hline 0 & $21(9.33)$ \\
\hline 1 & $100(44.44)$ \\
\hline 2 & $40(17.78)$ \\
\hline $3+$ & $64(28.44)$ \\
\hline Ulcer painful & \\
\hline No & $108(31.49)$ \\
Yes & $235(68.51)$ \\
\hline Ulcer pain intensity & \\
\hline Tolerable pain & $168(70.59)$ \\
\hline Pain that requires relief with analgesic & $66(27.73)$ \\
\hline Intolerable pain & $4(1.68)$ \\
\hline Prior sores in the genital area & \\
\hline
\end{tabular}

Continued 


\begin{tabular}{ll}
\hline Table 1 Continued & \\
\hline Characteristic & Value(n=387) \\
\hline No & $156(41.38)$ \\
Yes & $220(58.36)$ \\
On antiretroviral & \\
No & $324(97.30)$ \\
Yes & $9(2.70)$ \\
Number of ulcers & \\
1 & $157(41.0)$ \\
$2-5$ & $186(48.69)$ \\
$6+$ & $38(9.95)$ \\
Number of blisters & \\
None & $345(91.27)$ \\
$1-5$ & $25(6.61)$ \\
$6+$ & $8(2.12)$
\end{tabular}

Data are $\mathrm{n}(\%)$ participants, unless otherwise stated. Missing values are not included in the table. The denominator varies based on the number of subject's responses to each question or the test done at physical exams.

OR $0.3,95 \%$ CI 0.1 to $1.1, p=0.05$, respectively). Men who reported tolerable ulcer pain were less likely to acquire TV compared with men with intolerable ulcer pain (OR 0.08, $95 \%$ CI 0.007 to $1.1, \mathrm{p}=0.05$ ). There were no significant associations between TV and other factors including age, education and marital status.

\section{DISCUSSION}

We found that severe forms of ulceration were significantly associated with the risks for TV infection. Specifically, after adjusting for other factors $(p=0.002$ and $p=0.05)$, we found that men were less likely to have TV infection if they had painful ulcers and longer durations with ulcers. It is likely that the condition of the ulcers prevented some men from engaging in sexual activities with their partners. The odds of TV infection were higher among men who had high blister counts and lower among men who frequently sought treatment $(\mathrm{p}=0.01$ and $\mathrm{p}=0.005)$. The blisters sometimes bled during sex, creating a portal for the facilitation of TV and HIV infection. This is consistent with several STD studies. ${ }^{4514}$ A study on this same population published elsewhere found that men with TV infection had higher ulcer HIV loads on average than men who were not infected. ${ }^{8}$ The results of our study on ulceration are consistent with that finding. This condition may have a positive impact on the onward HIV transmission to uninfected sexual partners. There was significant association between TV infection $(\mathrm{p}<0.0001)$ among men who reported having an average of 1.4 regular partners and an average of 3.4 sex per week. This finding is consistent with results from similar studies in that region ${ }^{13} 1416$ and re-affirms the sexually active nature of the study population. Men from the Sotho ethnic group had increased odds for
TV infection after adjusting for other covariates (OR 8.6, $95 \%$ CI 1.3 to 55.7, $\mathrm{p}=0.02$ ). Also, men who were unqualified workers were more likely to have TV infection than those who were not $(\mathrm{p}=0.05)$. This may indicate inequity in accessing and affording healthcare services as reported in some studies. ${ }^{910}$ Our study found no significant association between circumcision, condom use and TV infection $(\mathrm{p}=0.3)$, confirming reports from a randomised controlled trial conducted in Kenya. ${ }^{17}$ All the ethnic groups that presented for the study are known to have low circumcision practices except for the Sotho ethnic group, which consisted of only $8.79 \%$ of the study participants. ${ }^{1819}$ Sexual risk behaviour studies among South African men indicated that the percentage of South African men who used a condom the last time they had sex ranged from $53 \%$ to $57 \%$ for young men. ${ }^{18-20}$ This study found low and inconsistent condom use among regular and casual sexual partners (29.88\% and $30.36 \%$, respectively; table 1$)$ and no significant association with TV infection $(p=0.3)$. This outcome may be due to cultural beliefs and practices around condom use in South Africa. ${ }^{21}$ Other sociodemographic variables including antiretroviral usage, circumcision, age and occupation were not significantly associated with the risk of TV infection in the bivariate analysis.

The main limitation of the study is participants' report on sexual behaviours. Since the interviews relied heavily on the men's ability to recall, some of them may have under-reported on some of the sexual behaviour questions. Another limitation is that all the men in the study had GUD and were HIV positive. Thus, this population was already at risk for TV and other STIs. A further limitation of this cross-sectional study is that the relatively small sample size restricts findings to this population and, thus, cannot be generalised to all HIV-positive men with GUD in South Africa. A final limitation of the study is that nearly $50 \%$ of the sample were non-South African native men. The criteria for inclusion in the trial were men living in South Africa with GUD. Thus, non-native South African men with GUD living in South Africa were not excluded from the trial. Although men from the Sotho ethnic group were more associated with TV infection, we could only restrict this finding to the study due to the small number of men from this ethnic group.

In conclusion, TV infection risks were more associated with ethnicity (Sotho) which showed increased odds after adjusting for all other covariates than with other sociodemographic factors. Also, men with risky sexual behaviours, severe forms of GUD and increased periods of ulceration were less associated with TV infection. This outcome has clinical implications for TV infection and HIV transmission, especially in South Africa, which has the highest HIV and STD burden and the lowest screening initiatives. ${ }^{22}$ The amplifying effect of TV on ulcer HIV viral load plays a key role in HIV transmission due to synergistic relationships between TV and HIV-1, especially among men. Hence, there is a need for intensified screening and treatment of TV in STD clinics. Though the addition of metronidazole to GUD treatment 
Open Access

Table 2 Characteristics associated with TV infection among study participants, South Africa, 2006

\section{Characteristic}

Age (years)

$35+$

$18-24$

25-34

Ethnic group

Other
Xhosa
Zulu

Sotho

Tsonga

Nationality

Other

South African

Occupation

\begin{tabular}{|c|c|c|c|c|}
\hline Other & 67/387 (17.3) & 6/387 (1.5) & 1.0 & \\
\hline Unqualified worker & $87 / 387(22.4)$ & 20/387 (5.1) & 2.5 (0.9 to 6.7$)$ & 0.05 \\
\hline Qualified worker & 63/387 (16.2) & $4 / 387(1.0)$ & 0.7 (0.1 to 2.6$)$ & 0.6 \\
\hline Unemployed & 126/387 (32.5) & 14/387 (3.6) & 1.2 (0.4 to 3.3$)$ & 0.6 \\
\hline \multicolumn{5}{|l|}{ Level of education } \\
\hline No school & 22/386 (5.7) & 5/386 (1.3) & 1.0 & \\
\hline >Primary & 63/386 (16.3) & 14/386 (3.6) & 0.9 (0.3 to 3.0) & 0.9 \\
\hline >High school & 257/386 (66.5) & $25 / 386(6.4)$ & 0.4 (0.1 to 1.2$)$ & 0.1 \\
\hline \multicolumn{5}{|l|}{ Marital status } \\
\hline Single & 186/387 (48.1) & $18 / 387(4.6)$ & 1.0 & \\
\hline Married/cohabitating & $140 / 387(36.2)$ & 22/387 (5.7) & $1.6(0.8$ to 3.1$)$ & 0.1 \\
\hline Divorced/separated/widowed & $17 / 387(4.4)$ & $4 / 387(1.1)$ & 2.4 (0.7 to 8.0$)$ & 0.1 \\
\hline \multicolumn{5}{|l|}{ Circumcision } \\
\hline No & $151 / 200(75.5)$ & $24 / 200(12.0)$ & 1.00 & \\
\hline Yes & $24 / 200(12.0)$ & $1 / 200(0.50)$ & 3.4 (0.5 to 24.2$)$ & 0.3 \\
\hline \multicolumn{5}{|l|}{ On antiretroviral } \\
\hline No & $257 / 300(85.6)$ & $34 / 300(11.3)$ & 1.0 & \\
\hline Yes & $9 / 300(3.0)$ & $0(0.0)$ & & 0.6 \\
\hline \multicolumn{5}{|l|}{ Prior sores in the genital area } \\
\hline No & 115/335 (34.32) & $21 / 335(6.26)$ & 1.0 & \\
\hline Yes & $181 / 335(54.02)$ & $18 / 335(5.37)$ & 0.5 (0.2 to 1.1$)$ & 0.06 \\
\hline \multicolumn{5}{|l|}{ Ulcer painful } \\
\hline No & $116 / 381(30.1)$ & 6/381 (1.6) & 1.00 & \\
\hline Yes & 226/381 (58.6) & 38/381 (9.8) & $0.3(0.2$ to 0.8$)$ & 0.006 \\
\hline \multicolumn{5}{|l|}{ Ulcer pain intensity } \\
\hline Tolerable pain & $154 / 246(62.6)$ & $18 / 246(7.3)$ & 1.00 & \\
\hline Intolerable pain & $55 / 246(22.4)$ & $19 / 246(7.7)$ & 0.4 (0.2 to 0.7$)$ & 0.003 \\
\hline \multicolumn{5}{|l|}{ Number of days with ulcers } \\
\hline $0-5$ & $161 / 338(47.6)$ & $11 / 338(3.3)$ & 1.00 & \\
\hline $6-10$ & 83/338 (24.6) & 13/338 (3.8) & 2.0 (0.9 to 4.4$)$ & 0.08 \\
\hline $11+$ & $55 / 338(16.3)$ & $15 / 338(4.4)$ & 3.3 (1.5 to 7.3$)$ & 0.002 \\
\hline
\end{tabular}

Continued

TV negative $\mathrm{n} / \mathrm{N}(\%) \quad$ TV positive $\mathrm{n} / \mathrm{N}(\%) \quad$ OR $(95 \% \mathrm{Cl})$

p Value

$\begin{array}{llll}109 / 387(28.2) & 17 / 387(4.4) & 1.0 & \\ 45 / 387(11.6) & 4 / 387(1.0) & 0.6(0.2 \text { to } 1.8) & 0.3 \\ 189 / 387(48.8) & 23 / 387(5.9) & 0.8(0.4 \text { to } 1.5) & 0.5\end{array}$

$108 / 387(27.9) \quad 7 / 387(1.8) \quad 1.0$

$14 / 387(3.6)$

$156 / 387(40.3)$

$3 / 387(0.7)$

3.3 (0.7 to 14.2$)$

0.1

2.1 (0.8 to 5.2$) \quad 0.08$

29/387 (7.4)

$5 / 387(1.2)$

2.6 (0.7 to 9.0$)$

0.1

$7 / 387$ (1.8)

3.0 (0.9 to 9.1$)$

0.05

$90 / 385(23.3)$

$10 / 385(2.5)$

1.0

251/385 (65.1)

$34 / 385(8.8)$

1.2 (0.5 to 2.5$)$

0.6

Other

Unqualified worker

$67 / 387(17.3)$

$6 / 387(1.5)$

1.0

Qualified worke

$63 / 387$ (16.2)

$4 / 387(1.0)$

$0.7(0.1$ to 2.6$)$

0.6

Unemployed

$22 / 386(5.7)$

$5 / 386(1.3)$

1.0

9 (0.3 to 3.0$)$

0.9

$>$ High school

257/386 (66.5)

$14 / 386(3.6)$

0.4 (0.1 to 1.2)

$\sum_{\substack{c \\ \hdashline}}^{\infty}$ 


\section{Table 2 Continued}

\section{Characteristic}

Seek care elsewhere before clinic

No

Yes

Number of times sought care

\begin{tabular}{|c|c|c|c|c|}
\hline 0 & 45/113 (39.8) & 0.00 & 1.00 & \\
\hline $1+$ & $58 / 113(51.3)$ & $10 / 113(8.9)$ & 0.07 (0.002 to 1.2$)$ & 0.005 \\
\hline \multicolumn{5}{|l|}{ Current regular partner } \\
\hline Yes & 297/385 (77.1) & $40 / 385$ (10.3) & $1.4(0.5$ to 4.3$)$ & 0.4 \\
\hline \multicolumn{5}{|l|}{ Number of regular partners } \\
\hline 1 & 239/342 (69.8) & 27/342 (7.8) & & 0.9 \\
\hline $2+$ & $53 / 342(15.4)$ & $12 / 342(3.5)$ & & 0.9 \\
\hline \multicolumn{5}{|l|}{ Number of regular partners } \\
\hline $\begin{array}{l}\text { Mean number, 95\% Cl (ref. TV } \\
\text { negative) }\end{array}$ & $39 / 344(11.3)$ & $304 / 343(88.6)$ & $1.4(0.6$ to 1.5$)$ & $<0.0001$ \\
\hline \multicolumn{5}{|l|}{ Number of times had sex last week } \\
\hline None & $149 / 340(43.8)$ & 19/340 (5.5) & 1.0 & \\
\hline $1-5$ & $144 / 340(42.3)$ & $18 / 340(5.2)$ & $0.9(0.4$ to 1.7$)$ & 0.7 \\
\hline $6+$ & $8 / 340(2.3)$ & $2 / 340(0.5)$ & 2.2 (0.5 to 8.9$)$ & 0.2 \\
\hline \multicolumn{5}{|l|}{ Number of times had sex last week } \\
\hline $\begin{array}{l}\text { Mean number, 95\% Cl (ref. TV } \\
\text { negative) }\end{array}$ & $339 / 383(88.5)$ & $44 / 383(11.4)$ & $3.4(-1.1$ to 7.9$)$ & $<0.0001$ \\
\hline \multicolumn{5}{|l|}{ Number of ulcers } \\
\hline $1-5$ & $306 / 381(80.3)$ & $37 / 381(9.7)$ & 1.0 & \\
\hline Never & 169/338 (50.0) & $18 / 338(5.3)$ & 1.0 & \\
\hline Sometimes/most of the time & $86 / 338(25.4)$ & $15 / 338(4.4)$ & $1.6(0.7$ to 3.4$)$ & 0.1 \\
\hline Always & $45 / 338(13.3)$ & $5 / 338(1.4)$ & $1.0(0.3$ to 2.9$)$ & 0.9 \\
\hline \multicolumn{5}{|c|}{ Condom use with casual partner/3 months } \\
\hline Never & $48 / 96(50.0)$ & $8 / 96(8.3)$ & 1.0 & \\
\hline Sometimes/most of the time & 22/96 (22.9) & $2 / 96(2.0)$ & $0.4(0.08$ to 2.0$)$ & 0.2 \\
\hline Always & 16/96 (16.6) & 2/96 (2.0) & $0.6(0.1$ to 3.0$)$ & 0.5 \\
\hline
\end{tabular}

Data are number of participants (\%), unless otherwise stated. Missing values are not included in the table. The denominator varies based on the number of subject's responses to each question or the test done at physical exams.

TV, Trichomonas vaginalis.

algorithm may help control TV infections as reported by the original trial, ${ }^{4}$ this approach is not likely to reduce the incidence of TV if it is not supported by culturally tailored interventions that address stigma. Future studies should examine the impact of sociocultural norms and the extent to which they account for non-associations 
Open Access

Table 3 Multivariate analysis of factors associated with Trichomonas vaginalis infection among men with GUDs, South Africa, 2006

\section{Characteristics}

Adjusted OR (95\% Cl)

\section{p Value}

Age in years

$35+$

1.0

$18-24$

$1.3(0.2$ to 7.9$)$

0.80

25-34

1.0 (0.3 to 3.2$)$

0.97

Ethnic group

Other

1.00

Xhosa

4.2 (0.3 to 56.4$)$

0.28

Zulu

$1.6(0.4$ to 5.8$)$

0.48

Sotho

8.6 (1.3 to 55.7 )

0.02

Tsonga

1.1 (0.2 to 7.5$)$

0.90

Marital status

Single $\quad 1.0$

Married/cohabitating

Divorced/separated/widowed

1.0

0.8 (0.5 to 3.7$)$

0.74

0.7 (0.06 to 11.1$)$

0.90

Occupation

Other

1.00

Unqualified worker

2.1 (0.4 to 13.2$)$

0.43

Qualified worker

$1.6(0.2$ to 12.8$)$

0.66

Unemployed

$1.4(0.2$ to 9.7$)$

0.74

Level of education

No school $\quad 1.00$

$>$ Primary

$1.4(0.4$ to 4.9$)$

0.60

$>$ High school

0.5 (0.03 to 6.3 )

0.60

Ulcer pain intensity
Tolerable pain
1.00
Intolerable
0.08 (0.007 to 1.1$)$
0.05

Prior sores in the genital area

$\begin{array}{lll}\text { Yes } & 1.0 & \\ \text { No } & 1.5(0.5 \text { to } 4.2) & 0.4\end{array}$

Number of days with ulcer

\begin{tabular}{|c|c|c|}
\hline $0-5$ & 1.0 & \\
\hline $6-10$ & $0.1(0.04$ to 0.5$)$ & 0.002 \\
\hline $11+$ & $0.3(0.1$ to 1.0$)$ & 0.05 \\
\hline \multicolumn{3}{|c|}{ Current regular partners } \\
\hline No & 1.00 & \\
\hline Yes & $1.1(0.7$ to 1.7$)$ & 0.68 \\
\hline \multicolumn{3}{|c|}{ Condom use with regular partners } \\
\hline Always & 1.0 & \\
\hline Sometimes & $0.9(0.2$ to 4.1$)$ & 0.9 \\
\hline Never & 0.5 (0.1 to 2.2$)$ & 0.3 \\
\hline \multicolumn{3}{|c|}{ Seek care elsewhere before coming to clinic } \\
\hline Yes & 1.0 & \\
\hline No & $3.0(0.2$ to 44.6$)$ & 0.4 \\
\hline
\end{tabular}

Adjusted for all the variables listed on the table. 
between TV and key high-risk behaviours (partner count, condom use, etc) or sociodemographic factors including circumcision, antiretroviral usage, age and occupation.

Correction notice This article has been corrected since it was published Online First. A Table 1 footnote has been added in.

Acknowledgements The authors would like to thank Maya Sternberg and Gabriela Paz-Bailey who provided the data for the study. The authors would also like to thank the faculty and staff of the Morehouse School of Medicine's Master of Public Health Program: Stephanie Miles-Richardson, Elaine Archie-Booker, Reinetta Waldrop, NyThea Tolbert, Carla Durham-Walker, Angela Wimes and Brenton Powers.

Contributors IA wrote the first draft of the manuscript with input from Elizabeth, AM. Ernest, AM led the data analysis. Elizabeth, AM and CJ finalized and edited the final manuscript. Original thesis committee members Elizabeth, AM, CJ and Lee, $\mathrm{C}$ supervised and helped organise the thesis structure for the MPH program. Carla Durham-Walker and Angela Wimes edited the final thesis. All authors reviewed and approved the final manuscript.

Competing interests None declared.

Ethics approval This study was conducted with the approval from the Morehouse School of Medicine Institutional Review Board (protocol \#375197).

Provenance and peer review Not commissioned; externally peer reviewed.

Data sharing statement № additional data are available. However, data sharing request relating to this particular study is to be made to the principal investigators: Dr Gabriela Paz-Bailey and Dr Maya Sternberg of the Centers of Disease Control and Prevention.

Open Access This is an Open Access article distributed in accordance with the Creative Commons Attribution Non Commercial (CC BY-NC 4.0) license, which permits others to distribute, remix, adapt, build upon this work non-commercially, and license their derivative works on different terms, provided the original work is properly cited and the use is non-commercial. See: http://creativecommons.org/ licenses/by-nc/4.0/

(C) Article author(s) (or their employer(s) unless otherwise stated in the text of the article) 2017. All rights reserved. No commercial use is permitted unless otherwise expressly granted.

\section{REFERENCES}

1. Trichomoniasis: CDC Fact Sheet. http://www.cdc.gov/std/ trichomonas/STDFact-Trichomoniasis.htm (Retrieved 9 Feb 2017).

2. Sobngwi-Tambekou J, Taljaard D, Nieuwoudt M, et al. Male circumcision and Neisseria gonorrhoeae, Chlamydia trachomatis and Trichomonas vaginalis: observations after a randomised controlled trial for HIV prevention. Sex Transm Infect 2009;85:116-20.

3. McClelland RS, Sangare L, Hassan WM, et al. Infection with Trichomonas vaginalis increases the risk of HIV-1 acquisition. $J$ Infect Dis 2007;195:698-702.

4. Johnson LF, Coetzee DJ, Dorrington RE. Sentinel surveillance of sexually transmitted infections in South Africa: a review. Sex Transm Infect 2005;81:287-93.
5. Kapiga S, Kelly C, Weiss S, et al. Risk factors for incidence of sexually transmitted infections among women in South Africa, Tanzania, and Zambia: results from HPTN 055 study. Sex Transm Dis 2009;36:199-206.

6. Gray RH, Wawer MJ, Sewankambo NK, et al. Relative risks and population attributable fraction of incident HIV associated with symptoms of sexually transmitted diseases and treatable symptomatic sexually transmitted diseases in Rakai District, Uganda. Rakai Project Team. AIDS 1999;13:2113-23.

7. Gray RH, Wawer MJ, Brookmeyer R, et al. Probability of HIV-1 transmission per coital act in monogamous, heterosexual, HIV-1discordant couples in Rakai, Uganda. Lancet 2001;357:1149-53.

8. Paz-Bailey G, Sternberg M, Puren AJ, et al. Determinants of HIV type 1 shedding from genital ulcers among men in South Africa. Clin Infect Dis 2010;50:1060-7.

9. Kalichman SC, Cain D, Simbayi LC. Multiple recent sexual partnerships and alcohol use among sexually transmitted infection clinic patients, Cape Town, South Africa. Sex Transm Dis 2011;38:18-23.

10. Guthrie BL, Kiarie JN, Morrison S, et al. Sexually transmitted infections among HIV-1-discordant couples. PLoS One 2011;4:e8276.

11. Gross G, Tyring SK. Sexually Transmitted Infections and Sexually Transmitted Diseases: Springer-Verlag Berlin Heidelberg, 2011.

12. Mah TL, Halperin DT. Concurrent sexual partnerships and the HIV epidemics in Africa: evidence to move forward. AIDS Behav 2010;14:11-16.

13. Paz-Bailey G, Sternberg M, Puren AJ, et al. Improvement in healing and reduction in HIV shedding with episodic acyclovir therapy as part of syndromic management among men: a randomized, controlled trial. J Infect Dis 2009;200:1039-49.

14. Lewis DA, Marsh K, Radebe F, et al. Trends and associations of Trichomonas vaginalis infection in men and women with genital discharge syndromes in Johannesburg, South Africa. Sex Transm Infect 2013;89:523-7.

15. World Bank. South Africa Overview. 2016. http://www.worldbank.org/ en/country/southafrica/overview (accessed 16 Feb 2017).

16. Delany-Moretlwe S, Abdolrazoli A, Clayton T, et al. Trichomonas vaginalis is associated with hiv-1 in high-risk migrant men and women living in inner-city settlements in Johannesburg, South Africa. London, UK 18th International Society for Sexually Transmitted Diseases Research Conference (2009), London, UK.

17. Mehta SD, Moses S, Agot K, et al. Adult male circumcision does not reduce the risk of incident Neisseria gonorrhoeae, Chlamydia trachomatis, or Trichomonas vaginalis infection: results from a randomized, controlled trial in Kenya. J Infect Dis 2009;200:370-8.

18. Byakika-Tusiime J. Circumcision and HIV infection: assessment of causality. AIDS Behav 2008;12:835-41.

19. Dehne KL, Riedner G. Sexually Transmitted Infections among Adolescents: The Need for Adequate Health Care, 2005. https:// www.giz.de/Themen/de/dokumente/en-sexually-transmittedinfections-2005.pdf

20. Vincent L. 'Boys will be boys': traditional Xhosa male circumcision, HIV and sexual socialisation in contemporary South Africa. Cult Health Sex 2008;10:431-46.

21. Ahmed S, Lutalo T, Wawer M, et al. HIV incidence and sexually transmitted disease prevalence associated with condom use: a population study in Rakai, Uganda. AIDS 2001;15:2171-9.

22. Rispel LC, Metcalf CA, Cloete A, et al. HIV prevalence and risk practices among men who have sex with men in two South African cities. J Acquir Immune Defic Syndr 2011;57:69-76. 